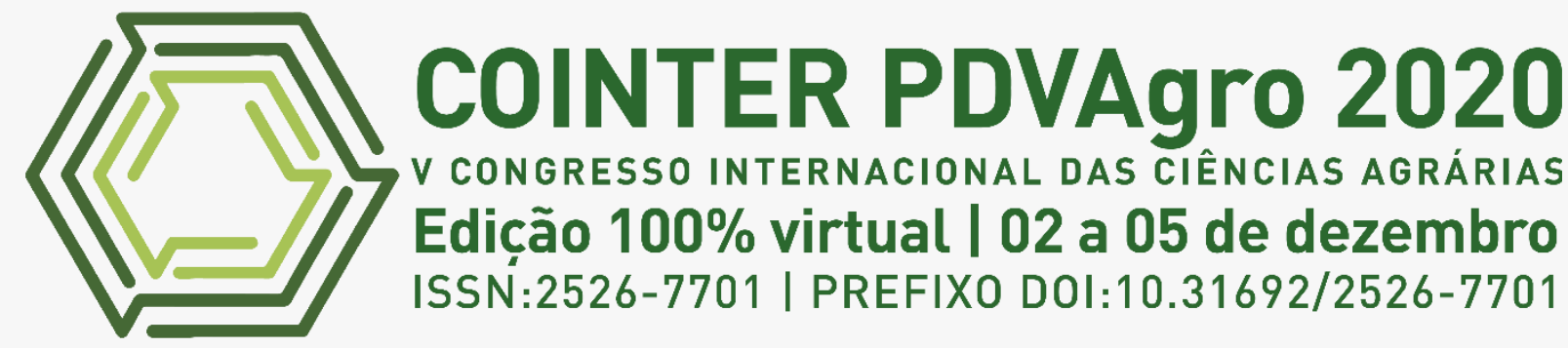

\title{
SOBREVIVÊNCIA DE RIZÓBIO EM SEMENTES DE FEIJÃO-CAUPI TRATADAS COM FUNGICIDA E INOCULANTE FORMULADO COM POLÍMERO GOMA XANTANA
}

\author{
SURVIVAL OF RHIZOBIA IN COWPEA BEAN SEEDS TREATED WITH \\ FUNGICIDE AND INOCULANT FORMULATED WITH GUMA XANTAN \\ POLYMER
}

\section{SUPERVIVENCIA DE RHIZÓBIO EN SEMILLAS DE CAUPÍ TRATADAS CON FUNGICIDA E INOCULANTE FORMULADO CON POLÍMERO DE GUMA XANTAN}

\author{
Apresentação: Comunicação Oral
}

Vanessa Cristina Macêdo Reis ${ }^{1}$; Delineide Pereira Gomes ${ }^{2}$; Thiago Palhares Farias ${ }^{3}$; José Flavio Ferreira de Sousa $^{4}$; Jean Magalhães da Silva ${ }^{5}$

DOI: https://doi.org/10.31692/2526-7701.VCOINTERPDVAgro.0215

\begin{abstract}
RESUMO
As bactérias fixadoras de nitrogênio promovem benefícios na produção vegetal, em especial na produtividade de leguminosas, tais como o feijão caupi. Apesar de resultados promissores dos inoculantes agrícolas, diversos fatores influenciam a eficiência dessa tecnologia. Por exemplo, o tratamento com fungicida associado ao inoculante pode reduzir a sobrevivência de rizóbios nas sementes. O objetivo do trabalho foi avaliar a sobrevivência de um rizóbio em sementes de feijão-caupi tratadas com fungicida carbendazin e com inoculantes líquidos formulados com goma xantana como veículo, em diferentes concentrações e períodos de armazenamento das sementes. Sementes de feijãocaupi cv. BRS Aracê foram inoculados com uma estirpe de Bradyrhizobium sp. O polímero goma xantana foi formulado em dez concentrações para uso nas formulações. Uma vez obtidas as formulações de inoculantes, estas foram associadas ao fungicida carbendazim na dose recomendada para o tratamento de sementes. A sobrevivência da estirpe do rizóbio, em cada concentração, foi avaliada aos $0,1,2,3,4$, 12, 24, 96, 192 e $768 \mathrm{~h}$ de armazenamento das sementes tratadas com esses produtos. O número de células viáveis foi obtido pela contagem das unidades formadoras de colônias, pelo método das diluições seriadas. A partir da diluição $10^{-1}$, alíquota de $1.0 \mathrm{~mL}$ de cada formulação foi diluída sucessivamente até $10^{-9}$. O polímero de goma Xantana, na concentração de 0.75 e $2.0 \mathrm{~g} \mathrm{~L}^{-1}$, promoveu boa viabilidade celular, porém não houve padrão de crescimento no número de células viáveis do microrganismo
\end{abstract}

\footnotetext{
${ }^{1}$ Graduanda em Licenciatura em Ciências Agrárias, Instituto Federal do Maranhão, Campus São Luís - Maracanã, E-mail: vanessa04rengav@gmail.com

${ }^{2}$ Doutora em Fitotecnia, Professora do Instituto Federal do Maranhão, Campus São Luís - Maracanã, E-mail: delineide.gomes@ifma.edu.br

${ }^{3}$ Engenheiro Agrônomo. Doutor em Ciência do Solo, Instituto Federal do Maranhão, Campus São Luís Maracanã, E-mail: thiagopalhares@ifma.edu.br

${ }^{4}$ Engenheiro Agrônomo, Instituto Federal do Maranhão, Campus Caxias. E-mail: jose.ferreira@ifma.edu.br

${ }^{5}$ Engenheiro Agrônomo, Instituto Federal do Maranhão, Campus São Raimundo das Mangabeiras, E-mail: jean.magalhaes@ifma.edu.br
} 


\title{
SOBREVIVÊNCIA DE RIZÓBIO EM SEMENTES DE FEIJÃO CAUPI TRATADAS
}

estudado em função das concentrações do polímero goma xantana e dos períodos de armazenamento das sementes tratadas. Mesmo sem a observação desse padrão de crescimento, a combinação do inoculante veiculado pela goma xantana com o fungicida carbendazim permite a sobrevivência do rizóbio estudado, em muitas das concentrações do polímero e em alguns dos períodos de armazenamento das sementes avaliados no presente estudo.

Palavras-chave: Vigna unguiculata (L.) Walp, Bradyrhizobium sp., Biopolímeros

\section{RESUMEN}

Las bacterias fijadoras de nitrógeno promueven beneficios en la producción vegetal, especialmente en la productividad de leguminosas, como el caupí. A pesar de los resultados prometedores de los inoculantes agrícolas, varios factores influyen en la eficiencia de esta tecnología. Por ejemplo, el tratamiento con fungicida asociado con el inoculante puede reducir la supervivencia de los rizobios en las semillas. El objetivo del trabajo fue evaluar la supervivencia de un rizobio en semillas de caupí tratadas con fungicida carbendazina y con inoculantes líquidos formulados con goma xantana como vehículo, en diferentes concentraciones y períodos de almacenamiento de las semillas. Semillas de caupí cv. BRS Aracê se inoculó con una cepa de Bradyrhizobium sp. El polímero de goma de xantano se formuló en diez concentraciones para su uso en las formulaciones. Una vez obtenidas las formulaciones de inoculantes, se asociaron con el fungicida carbendazim a la dosis recomendada para el tratamiento de semillas. La supervivencia de la cepa de rizobios, en cada concentración, se evaluó a las $0,1,2,3,4$, 12, 24, 96, 192 y 768 horas de almacenamiento de las semillas tratadas con estos productos. El número de células viables se obtuvo contando las unidades formadoras de colonias, utilizando el método de dilución en serie. A partir de la dilución $10^{-1}$, se diluyó sucesivamente una alícuota de $1,0 \mathrm{ml}$ de cada formulación hasta $10^{-9}$. El polímero de goma xantana, a una concentración de 0,75 y $2,0 \mathrm{~g} \mathrm{~L}^{-1}$, promovió una buena viabilidad celular, sin embargo no hubo patrón de crecimiento en el número de células viables de los rizobios estudiados debido a las concentraciones del polímero de goma xantana y los períodos de almacenamiento del semillas tratadas. Incluso sin observar este patrón de crecimiento, la combinación del inoculante transportado por la goma xantana con el fungicida carbendazim permite la supervivencia de los rizobios estudiados, en muchas de las concentraciones de polímero y en algunos de los períodos de almacenamiento de semillas evaluados en el presente investigación.

Palabras Clave: Vigna unguiculata (L.) Walp, Bradyrhizobium sp., Biopolímeros

\begin{abstract}
Nitrogen fixing bacteria promote benefits in plant production, especially in the productivity of legumes, such as cowpea. Despite promising results from agricultural inoculants, several factors influence the efficiency of this technology. For example, treatment with fungicide associated with the inoculant can reduce the survival of rhizobia in the seeds. The objective of the work was to evaluate the survival of a rhizobia in cowpea seeds treated with carbendazin fungicide and with liquid inoculants formulated with xanthan gum as a vehicle, in different concentrations and storage periods of the seeds. Seeds of cowpea cv. BRS Aracê were inoculated with a strain of Bradyrhizobium sp. The xanthan gum polymer was formulated in ten concentrations for use in the formulations. Once the inoculant formulations were obtained, they were associated with the fungicide carbendazim at the recommended dose for seed treatment. The survival of the rhizobia strain in each concentration was evaluated at $0,1,2,3,4,12,24$, 96, 192 and 768 hours of storage of the seeds treated with these products. The number of viable cells was obtained by counting the colony-forming units, using the serial dilution method. From the $10^{-1}$ dilution, a $1.0 \mathrm{~mL}$ aliquot of each formulation was diluted successively to $10^{-9}$. The xanthan gum polymer at a concentration of 0.75 and $2.0 \mathrm{~g} \mathrm{~L}^{-1}$ promoted good cellular viability, however there was no growth pattern in the number of viable cells of the rhizobia studied due to the concentrations of the xanthan gum polymer and the storage periods of the treated seeds. Even without observing this growth pattern, the combination of the inoculant transmitted by xanthan gum and the fungicide carbendazim allows the survival of the rhizobia studied, in many of the concentrations of the polymer and in some of the storage periods of the seeds evaluated in the present study.
\end{abstract}

Keywords: Vigna unguiculata (L.) Walp, Bradyrhizobium sp., Biopolymers 


\section{INTRODUÇÃO}

O feijão caupi é uma cultura adaptada a condições adversas tropicais, com bastante tolerância às intempéries, mas que ainda apresenta baixa produtividade em algumas regiões brasileiras (ALMEIDA et al, 2010; FARIAS, 2014; OLIVEIRA 2019). Entre os principais fatores que reduzem a produtividade do caupi no Nordeste, destacam-se o uso de cultivares com baixa capacidade produtiva e insuficiência de tecnologias voltadas para o seu cultivo e manejo (FREIRE FILHO et al, 2005; MONTEIRO et al., 2012; GUIMARÃES et al., 2020).

A simbiose do feijão-caupi com bactérias fixadoras de nitrogênio do ar (rizóbios) é um processo de suma importância, pois permite a captação e o uso mais eficiente do nitrogênio, gerando economia devido à redução de fertilizantes nitrogenados e diminui problemas ambientais da utilização destes insumos na agricultura (MOREIRA e SIQUEIRA, 2006; COSTA, 2018). A redução de adubos nitrogenados e o uso de rizóbios em sementes se racionaliza com os princípios agroecológicos, pois estimula a produção de alimentos nutritivos e seguros com a preservação dos seres vivos e do meio ambiente (ARIAS, 2016).

Inoculantes com formulações líquidas podem ser uma alternativa técnica viável à turfa, pois procuram reduzir os custos de produção, e facilitam a aplicação do produto na semente no momento da semeadura, bem como podem manter a sobrevivência e a eficiência do rizóbio em condições de campo. No entanto, as diferentes técnicas e veículos de inoculação, o uso de tratamento químico nas sementes, bem como o período de exposição a esses produtos, podem afetar significativamente a sobrevivência do rizóbio nas sementes (SCHUH, 2005).

Sabe-se que aplicação de fungicidas, além de outros agroquímicos sobre as sementes, traz inúmeros benefícios para as culturas de modo geral. Entretanto, estes produtos podem trazer efeitos negativos sobre a sobrevivência e no desempenho de rizóbios, podendo prejudicar a interação simbiótica e reduzir a fixação biológica do nitrogênio por esses organismos (CAMPO et al., 2003; SILVA NETO et al., 2013; SANTOS et al., 2018). Assim, o uso de determinados insumos pode reduzir a eficiência do rizóbio e competir para o lançamento de novas formulações mais viáveis e eficientes. Neste cenário, pesquisas devem ser realizadas para verificar a interação dos rizóbios com produtos que são aplicados normalmente sobre as sementes, tais como os fungicidas, inseticidas, micronutrientes e outros.

Para o feijão caupi, ainda são insuficientes os estudos sobre a compatibilidade dos fungicidas de sementes com os diferentes tipos de inoculantes. Nesse contexto, o objetivo deste trabalho foi avaliar a compatibilidade de um fungicida usado no tratamento de sementes com um inoculante líquido formulado com goma xantana, em diferentes concentrações e períodos 
de armazenamento das sementes tratadas com esses produtos, sobre a sobrevivência de um rizóbio em sementes de feijão-caupi.

\section{FUNDAMENTAÇÃO TEÓRICA}

\section{A fixação biológica de nitrogênio (FBN) no feijão caupi}

Sabe-se que a FBN representa uma grande economia em comparação aos custos com a adubação química com fontes nitrogenadas, sendo que esse processo se dá através da inoculação de sementes com formulações apropriadas, técnica de custo acessível e de fácil operação (KUSDRA, 1998).

As bactérias fixadoras de nitrogênio atmosférico, ou rizóbios, pertencem principalmente aos gêneros Rhizobium, Bradyrhizobium, Azorhizobium, Sinorhizobium, Mesorhizobium. Sendo os dois primeiros, os mais mais estudados e com larga eficência na fixação de nitrogênio, geralmente para a família das fabáceas ou leguminosas (ZAHRAN, 1999; MERCANTE et al., 2002). A fixação simbiótica de nitrogênio se dá pela associação destes rizóbios com as raízes de plantas, com a formação de nódulos radiculares, mas que também podem ser vistos nos caules, no caso do gênero Azorhizobium (UDVARD e DAY,1997; MERCANTE et al., 2002).

Entre os benefícios dos rizóbios na agricultura, estão aqueles direcionados à germinação, emergência e crescimento inicial de plantas de várias culturas (SCHLINDWEIN et al., 2008; GARCIA et al., 2015; SOUZA, 2017). Por exemplo, sementes de Mimosa tenuiflora inoculadas com diferentes rizóbios pode apresentar aumento no IVG (índice de velocidade de germinação), no comprimento de raízes e na massa seca de plântulas (SANTOS et al., 2017). Em arroz, a inoculação de sementes com os rizóbios Sinorhizobium e Rhizobium elevou o IVG de plântulas (STROSCHEIN et al., 2011; SOUZA 2017).

Devido à tolerância para a adaptação em ambientes pouco favoráveis é que a cultura do caupi interage bem com rizóbios, facilitando os processos de FBN (MARTINS et al., 2003; ZILLI et al., 2006; VIEIRA et al., 2010). A cultura estabelece boa relação com Bradyrhizobium spp. e na literatura existem algumas pesquisas de inoculação deste rizóbio combinado ao uso de agroquímicos, dentre eles inseticidas, fungicidas, micronutrientes, etc (CAMPO et al., 2003; SILVA NETO et al., 2013; SANTOS et al., 2018). No entanto, pesquisas afirmam que estes produtos podem ter efeito deletério sobre os rizóbios, e, portanto podem reduzir a FBN, mas poucas relatam esse efeito deletério na sobrevivência do rizóbio estudado. 
REIS, et al.

\section{Tipos de inoculantes e o uso de polímeros como suporte para inoculantes}

No mercado brasileiro é grande a oferta de várias formulações de inoculantes para sementes, podendo existir vários veiculos além dos sólidos (como exemplo, a turfa), tais como formulações líquidas, a base de géis e as liofilizadas (SCHUH, 2005). O inoculante liquido tem como veículo um substrato aquoso esterilizado por onde se veicula os rizóbios. O veículo pó molhável é um substrato sólido, contendo rizóbios que foram liofilizados, necessitando ser hidratados antes da inoculação nas sementes. Já a turfa, veiculo sólido tradicional, é encontrada em solos aluviais orgânicos e ácidificados, necessitando ser extraida, triturada, peneirada, seca, esterilizada e corrigida quanto ao $\mathrm{pH}$, aumentando-o para próximo da neutralidade (SCHUH, 2005; SANTOS, 2011). Santos (2011) considera ser rigoroso esse processamento da turfa, tornando isso uma desvantagem, comparada a praticidade encontrada na manipulação de outros veículos, além disso, esse autor afirma que a turfa é uma fonte limitada, já ausente em alguns países, e que no futuro poderá se tornar um recurso escasso.

Polissacarídeos e derivados são largamente utilizados na indústria de alimentos em forma de pó hidratável, podendo ser utilizados como veículos nas formulações de inoculantes. Entre esses veículos estão as gomas naturais e as gomas modificadas. Entre as gomas naturais estão os extratos de algas marinhas, denominados de alginatos, a goma arábica que são provenientes de exsudatos de plantas, a goma jataí (composta por exsudatos de sementes ou de raízes) e a goma xantana, essa ultima produzida pela fermentação de certos microrganismos, principalmente bactérias do gênero Xanthomonas. As gomas modificadas são provenientes de derivados de amido celulose (LIPS et al.,1991).

A literatura relata que a goma xantana pode ser muito mais que um veículo para inoculação de rizóbios, sendo o biopolímero de origem bacteriana mais estudado na indústria alimentícia, pois seu uso em alimentos foi permitido pela FDA (Food and Drug Administration) desde de 1969 (FDA, 1969; SANTOS, 2011). Trata de um polímero biodegradável, atóxico, hidrossolúvel, obtido de fontes renováveis e de baixo custo (FERNANDES JUNIOR, 2006; SANTOS, 2011).

A legislação brasileira do Ministério de Agricultura, Pesca e Abastecimento (MAPA, DOU10/08/2004, Anexo I) recomenda que qualquer inoculante, sólido ou líquido, deve ser produzido com veiculos esterilizados, isentos de contaminação até o fator de diluição de $10^{-5}$, com validade de no minimo 6 meses (SCHUH, 2005). 


\section{Tratamento de sementes com fungicidas e inoculantes}

O tratamento de sementes é uma técnica imprescindível para a agricultura moderna. Seu objetivo é proteger as sementes ou adicionar os mais variados componentes físicos, químicos e biológicos relacionados ao metabolismo, nutrição e sanidade da plantas futuras (ZAMBOLIM, 2004; FERNANDES, 2010).

Em áreas extensas de plantio, o caupi tem recebido varias tecnologias quanto ao tratamento de sementes, tais como aplicação de rizóbios, inseticidas, fungicidas, micronutrientes e outros. Não há ainda, no presente momento, registro de fungicidas para o tratamento de sementes de feijão caupi, por isso os agricultores vêm adotado as recomendações aplicadas na soja e no feijão comum, com ingredientes a base de carbendazim, thiram, carboxin, fludioxonil, por exemplo (SILVA NETO, 2013).

Diversas pesquisas têm demonstrado a combinação viável de fungicidas com inoculantes na eficiência agronômica de várias culturas, porém poucos falam sobre esse efeito na sobrevivência de rizóbios. A exemplo destes escassos trabalhos têm se o de Kintschev et al. (2014), os quais verificaram, em feijoeiro comum, que a sobrevivência das estirpes de Rhizobium tropici + Rhizobium freirei em sementes foi afetada pela aplicação de diferentes fungicidas, principalmente pelos produtos com modo de ação por contato. Barbosa e Gonzaga (2012) recomendam utilizar produtos com menor toxidez e manter o inoculante em contato com o fungicida durante menor tempo possível.

\section{METODOLOGIA}

A pesquisa foi de natureza quantitativa e experimental. A mesma foi realizada no Laboratório de Biotecnologia/Microbiologia de Solos do IFMA Campus São Luis- Maracanã.

\section{Obtenções das sementes de feijão caupi}

Foi obtido um lote de sementes de feijão caupi da cultivar BRS Aracê. As sementes utilizadas nos experimentos passaram por tratamento com fungicida a base de carbendazin na dose de $200 \mathrm{~mL} / 100 \mathrm{~kg}$ de sementes do produto comercial. As sementes tratadas foram postas para secar em papel filtro esterilizado em temperatura ambiente.

\section{Obtenção do rizóbio: estirpe de referência e condições de crescimento}

A estirpe de rizóbio que foi utilizada foi a Bradyrhizobium sp. - UFLA 03-84 (= SEMIA 6461), eficiente na simbiose com o feijão caupi (LACERDA et al. 2004). A estipe foi cultivada em meio YMA(VINCENT, 1970) (10g L $\mathrm{L}^{-1}$ de manitol, 0,01g-1 de $\mathrm{K}_{2} \mathrm{HPO}_{4}, 0,04 \mathrm{~g} \mathrm{~L}^{-1}$ de 
$\mathrm{KH}_{2} \mathrm{PO}_{4}, 0,05 \mathrm{~g} \mathrm{~L}^{-1}$ de $\mathrm{MgSO}_{4} .7 \mathrm{H} 2 \mathrm{O}, 0,01 \mathrm{~g} \mathrm{~L}^{-1} \mathrm{NaCl}, 0,4 \mathrm{~g} \mathrm{~L}^{-1}$ de extrato de levedura em pó, $15 \mathrm{~g} \mathrm{~L}^{-1}$ agar, pH ajustado a 6,8-7,0) a $28{ }^{\circ} \mathrm{C}$ (adaptado de CARDILLO, 2015).

\section{Preparo das formulações do inoculante com o polímero goma xantana}

Foi utilizado o meio YMA como solução, descrito sucintamente: manitol $10 \mathrm{~g} \mathrm{~L}^{-1}$, como fonte de carbono. Foi utilizado o polímero Goma Xantana como veiculo nas formulações do inoculante. Após o preparo, as formulações foram esterilizadas em autoclave a $120{ }^{\circ} \mathrm{C}$. Para a padronização da concentração do inóculo, as estirpes foram inoculadas em Erlenmeyer (125,0 $\mathrm{mL}$ ), contendo 45,0 mL de meio YMA líquido (pH 6,8) e incubada em agitador orbital a 110 rpm e $28^{\circ} \mathrm{C}$, durante $72 \mathrm{~h}$, até densidade óptica de 0,5 a $600 \mathrm{~nm}$ (DO600), equivalente a $1,5 \times 10^{8}$ UFC $\mathrm{mL}^{-1}$ pela escala de McFarland. Posteriormente, uma alíquota de $0,1 \mathrm{~mL}$ do inóculo foi adicionada a frascos de vidro lavados com ácido e esterilizados com meio YMA líquido modificado. Os frascos foram distribuídos em uma incubadora a $110 \mathrm{rpm}$ e $28^{\circ} \mathrm{C}$ (adaptado de CARDILLO, 2015).

Para auxiliar a detecção de possíveis contaminações, por alterações em pH do meio durante a avaliação, tratamentos controles sem inoculação foram mantidos. Alíquotas de 0,1 $\mathrm{mL}$ do inóculo da estirpe inoculante UFLA 03-84 foi inoculada em cada uma das formulações. Posteriormente, as formulações foram transferidas para tubos de centrifugação em polipropileno fundo cônico, com tampa alongada à prova de vazamentos, com capacidade de $50 \mathrm{~mL}$, esterilizados por radiação gama. As amostras foram armazenadas em agitador orbital a $110 \mathrm{rpm}$ e $28^{\circ} \mathrm{C}$ (adaptado de CARDILLO, 2015).

\section{Inoculação das sementes de caupi tratadas com fungicida com as formulações do inoculante veiculadas pela goma xantana}

A inoculação do rizóbio nas sementes de caupi foi realizada após a aplicação do fungicida carbendazin. Após o tratamento fungicida, sementes de caupi foram inoculadas com dez concentrações do inoculante formulado com o veículo goma xantana, em lotes de 200 sementes, sendo selecionadas aleatoriamente do lote, com $500 \mu \mathrm{L}$ de inoculante líquido.

Em seguida, as sementes tratadas com esses produtos foram submetidas a dez períodos de armazenamento (0,1, 2, 3, 4, 12, 24, 96, 192 e 768 horas) e posteriormente avaliadas quanto à sobrevivência do rizóbio nas mesmas.

Avaliação da sobrevivência do rizóbio nas sementes tratadas com fungicida e inoculadas com as formulações líquidas do inoculante veiculadas pela goma xantana

A sobrevivência do rizóbio foi avaliada em sementes tratadas com fungicida e com as 


\section{SOBREVIVÊNCIA DE RIZÓBIO EM SEMENTES DE FEIJÃO CAUPI TRATADAS}

concentrações do inoculante veiculadas pela goma xantana, num total de dez concentrações, em dez períodos de armazenamento, com três repetições por tratamento.

Para isto, foi utilizado o método das diluições seriadas. Vinte sementes retiradas aleatoriamente de amostras com 200 sementes, de cada tratamento, foram colocadas em Erlenmeyer contendo $90 \mathrm{~mL}$ de solução salina $0,85 \%$ estéril e agitadas por 15 minutos, sendo considerada, então, a diluição $10^{-1}$. A partir dessa diluição, alíquota de $1,0 \mathrm{~mL}$ de cada formulação foi diluída sucessivamente até $10^{-9}$ (adaptado de CARDILLO, 2015).

Alíquotas de $20 \mu \mathrm{L}$ foram inoculadas em placas de Petri com meio YMA, por meio da técnica de microgotas, e secas na cabine bacteriológica durante 20 minutos antes de ser invertida e depois incubada a $28^{\circ} \mathrm{C}$, por um período de até 144 horas. As avaliações foram realizadas em quadruplicatas. O número de células viáveis foi determinado pela contagem de unidades formadoras de colônias (adaptado de CARDILLO, 2015).

O número de unidades formadoras de colônias por mililitro foi calculado utilizando a seguinte fórmula: Unidades Formadoras de Colônias $\left(\mathrm{UFC} \mathrm{mL}^{-1}\right)=$ Número de Colônias por diluição x Fator de diluição.

Em resumo, os tratamentos consistiram da combinação de dez concentrações em dez periodos de armazenamento, em delineamento inteiramente casualizado (DIC), porém nao foi realizada a análise estatistica em esquema fatorial, pois a análise fatorial só será realizada quando se obtiver os resultados finais com o tratamento das sementes com outros polimeros, além da goma xantana, os quais fazem parte de um projeto maior, justificando, portanto que esses dados sao preliminares, sem análise estatistica no momento.

\section{RESULTADOS E DISCUSSÃO}

Na Tabela 1, são apresentadas as concentrações do biopolímero goma xantana, obtidas experimentalmente, as quais foram utilizadas nas formulações para o tratamento das sementes de caupi. Inicialmente, foram feitos testes de consistência para se definir as concentrações do polímero, com ensaios para verificar as consistências adequadas das mesmas. Após esses testes, foram obtidas dez concentrações ideais do polímero.

Os dados apresentados estão expressos como médias obtidas na maior diluição $\left(10^{-9}\right)$, o que corresponde ao maior número de UFC por microlitro de inoculante.

Tabela1: Concentrações $\left(\mathrm{g} \mathrm{L}^{-1}\right)$ de polímeros sintéticos obtidas para o preparo das formulações do rizóbio visando à inoculação de sementes de feijão caupi.

Polímero

Concentrações obtidas $\left(\mathrm{g} \mathrm{L}^{-1}\right)$ 


\begin{tabular}{lllllllllll}
\hline $\begin{array}{l}\text { Goma } \\
\text { Xantana }\end{array}$ & 0.0 & 0.05 & 0.25 & 0.50 & 0.75 & 1.00 & 1.25 & 1.50 & 1.75 & 2.0 \\
\hline
\end{tabular}

Fonte: Própria (2020)

Essas concentrações obtidas no ensaio da goma xantana foram consideradas baixas, o que é desejável, pois se sabe que o uso de menores concentrações está diretamente relacionado ao custo menor quanto à utilização do polímero na indústria dos inoculantes.

A utilização da goma xantana nas concentrações de 0.75 e $2.0 \mathrm{~g} \mathrm{~L}^{-1}$ proporcionou, para a maioria dos períodos de armazenamento das sementes avaliadas, bons valores quanto ao numero de células viáveis da bactéria, em comparação com a ausência do polímero (concentração zero), ou seja, comparado à testemunha (Tabela 2).

Esse resultado demonstra que o uso da goma xantana pode ser viável como veiculo para a formulação de inoculantes com Bradyrhizobium sp., necessitando, porém, de reavaliação dessas concentrações, uma vez que as concentrações aqui obtidas, variando de 0.05 a $2.0 \mathrm{~g} \mathrm{~L}^{-1}$, nos períodos de armazenamento de $0,1,2,3,4,12$, 24, 96, 192 e 768 h, não permitiram obter um padrão de crescimento no número de células viáveis da estirpe estudada, ou seja, não houve um padrão de resposta na manutenção da viabilidade celular de Bradyrhizobium sp. (UFLA 0384), nas condições do presente estudo.

Tabela 2: Sobrevivência da estirpe Bradyrhizobium sp. UFLA 03-84 (= SEMIA 6461) em sementes de feijão-caupi tratadas com fungicida e submetidas à formulações de inoculante com o polímero Goma Xantana em diferentes concentrações e períodos de armazenamnto das sementes tratadas com esses produtos (dados da diluição de $10^{-9}$ ).

\begin{tabular}{|c|c|c|}
\hline $\begin{array}{l}\text { Concentrações } \\
\left(\mathrm{g} \mathrm{L}^{-1}\right)\end{array}$ & $\begin{array}{l}\text { Período de Armazenamento } \\
\text { (horas) }\end{array}$ & $\begin{array}{l}\text { UFC } \\
\text { (média) }\end{array}$ \\
\hline \multirow[t]{10}{*}{ 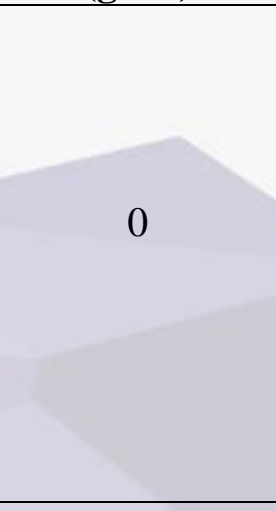 } & 0 & $10,5 \times 10^{-9}$ \\
\hline & 1 & $15,2 \times 10^{-9}$ \\
\hline & 2 & $3,4 \times 10^{-9}$ \\
\hline & 3 & $3,0 \times 10^{-9}$ \\
\hline & 4 & $8,0 \times 10^{-9}$ \\
\hline & 12 & $14,5 \times 10^{-9}$ \\
\hline & 24 & $3,0 \times 10^{-9}$ \\
\hline & 96 & $0,0 \times 10^{-9}$ \\
\hline & 192 & $0,0 \times 10^{-9}$ \\
\hline & 768 & $3,0 \times 10^{-9}$ \\
\hline \multirow{8}{*}{0.05} & 0 & $3,4,2 \times 10^{-9}$ \\
\hline & 1 & $44,1 \times 10^{-9}$ \\
\hline & 2 & $3,0 \times 10^{-9}$ \\
\hline & 3 & $18.8 \times 10^{-9}$ \\
\hline & 4 & $5,1 \times 10^{-9}$ \\
\hline & 12 & $22,5 \times 10^{-9}$ \\
\hline & 24 & $34,5 \times 10^{-9}$ \\
\hline & 96 & $16,3 \times 10^{-9}$ \\
\hline
\end{tabular}




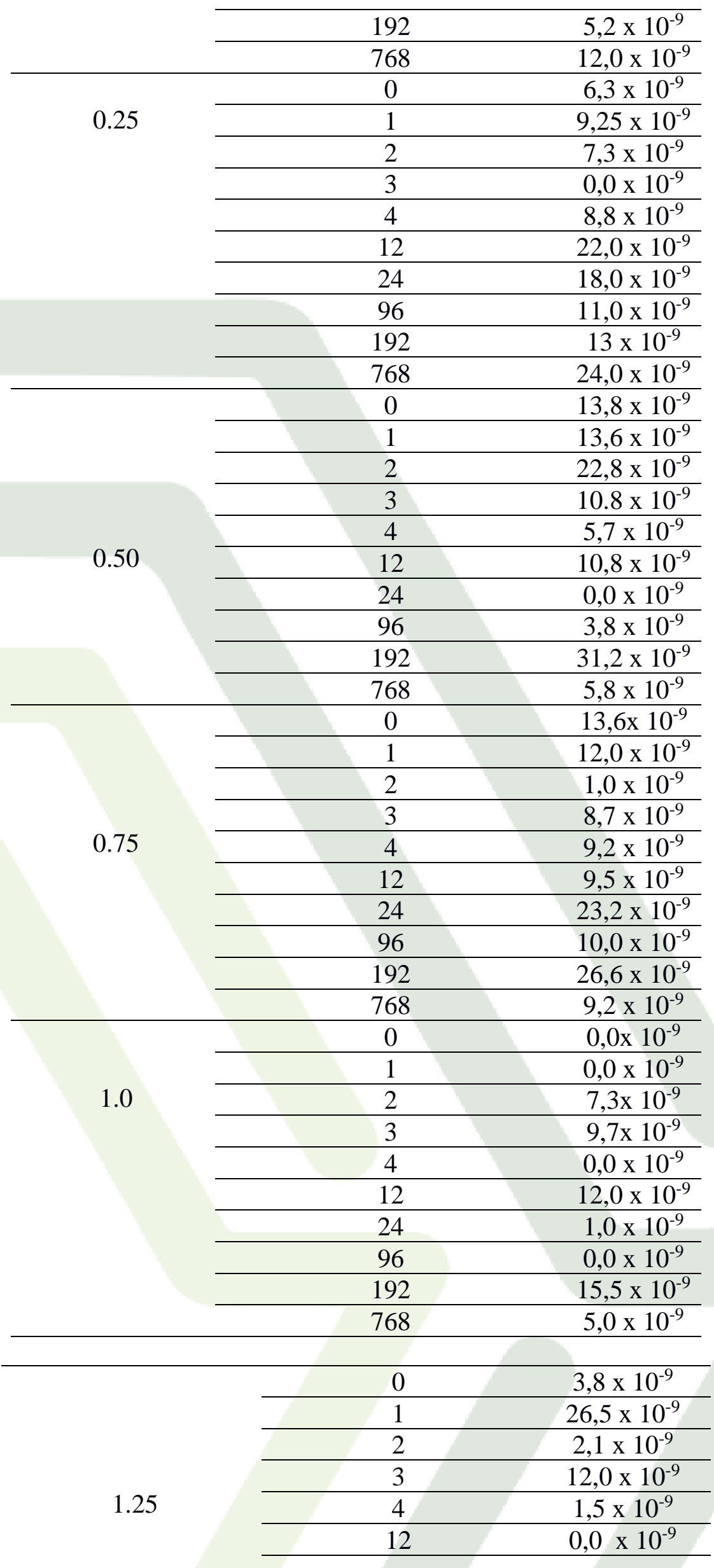

[10] 
REIS, et al.

\begin{tabular}{|c|c|c|}
\hline & & \\
\hline & 24 & $17,1 \times 10^{-9}$ \\
\hline & 96 & $1,0 \times 10^{-9}$ \\
\hline & 192 & $1,0 \times 10^{-9}$ \\
\hline & 768 & $23,8 \times 10^{-9}$ \\
\hline \multirow{10}{*}{1.50} & 0 & $0,0 \times 10^{-9}$ \\
\hline & 1 & $30,7 \times 10^{-9}$ \\
\hline & 2 & $1,0 \times 10^{-9}$ \\
\hline & 3 & $5,6 \times 10^{-9}$ \\
\hline & 4 & $0,0 \times 10^{-9}$ \\
\hline & 12 & $1,0 \times 10^{-9}$ \\
\hline & 24 & $12,0 \times 10^{-9}$ \\
\hline & 96 & $0,0 \times 10^{-9}$ \\
\hline & 192 & $27,5 \times 10^{-9}$ \\
\hline & 768 & $5,0 \times 10^{-9}$ \\
\hline \multirow{10}{*}{1.75} & 0 & $1,0 \times 10^{-9}$ \\
\hline & 1 & $3,8 \times 10^{-9}$ \\
\hline & 2 & $1,2 \times 10^{-9}$ \\
\hline & 3 & $14,25 \times 10^{-9}$ \\
\hline & 4 & $3,75 \times 10^{-9}$ \\
\hline & 12 & $1,5 \times 10^{-9}$ \\
\hline & 24 & $0,0 \times 10^{-9}$ \\
\hline & 96 & $3,14 \times 10^{-9}$ \\
\hline & 192 & $0,0 \times 10^{-9}$ \\
\hline & 768 & $20,0 \times 10^{-}$ \\
\hline \multirow{10}{*}{2.0} & 0 & $1,0 \times 10^{-9}$ \\
\hline & 1 & $8,11 \times 10^{-9}$ \\
\hline & 2 & $3,0 \times 10^{-9}$ \\
\hline & 3 & $8,0 \times 10^{-9}$ \\
\hline & 4 & $2,25 \times 10^{-9}$ \\
\hline & 12 & $1,0 \times 10^{-9}$ \\
\hline & 24 & $6,3 \times 10^{-9}$ \\
\hline & 96 & $2,0 \times 10^{-9}$ \\
\hline & 192 & $20,5 \times 10^{-9}$ \\
\hline & 768 & $14,27 \times 10^{-9}$ \\
\hline
\end{tabular}

UFC: Unidade Formadora de Colônia. Fonte: Própria (2020)

Em feijoeiro comum, Kintschev et al. (2014) verificaram que a sobrevivência das estirpes de Rhizobium tropici + Rhizobium freirei inoculadas em sementes foi afetada pela aplicação de diferentes fungicidas, principalmente por produtos com modo de ação por contato. Na presente pesquisa com sementes de caupi, foi utilizado um fungicida sistêmico, no caso o carbendazin, o qual, quando combinado com as concentrações do polímero goma xantana, não proporcionou um padrão de crescimento do rizóbio estudado, pois, ora houve o crescimento do número de células viáveis em algumas concentrações, ora houve a diminuição desses números em outras concentrações, não se demonstrando um padrão de manutenção de viabilidade celular nos períodos de armazenamento estudados. Porém, mesmo sem esse padrão de crescimento, foi 


\section{SOBREVIVÊNCIA DE RIZÓBIO EM SEMENTES DE FEIJÃO CAUPI TRATADAS}

constatada a sobrevivência do rizóbio em várias concentrações desse biopolímero, em vários períodos de armazenamento das sementes tratadas, pela observação de bons valores de UFC em comparação com a testemunha.

Santos et al. (2018), avaliando a combinação dos fungicidas tiofanato metílico + fluazinam com B. japonicum, verificaram que estes foram compatíveis no tratamento de sementes de caupi, pois não inibiram o crescimento da estirpe INPA03-11B in vitro.

Santos (2011), em feijão caupi cv. IPA 206, também demonstrou que goma xantana pode ser indicada como veículo para inoculação de uma estirpe de Bradyrhizobium sp. (BR3267), pois verificaram a sobrevivência e viabilidade desse rizóbio através do método de infecção plantas, mantendo densidade populacional do organismo superior à turfa, porém sem a avaliação de compatibilidade com fungicidas tal como foi realizado aqui.

A sobrevivência de rizóbios em formulações veiculadas por biopolímeros, tais como a goma xantana, pode ser atribuída à propriedade de "encapsular" células bacterianas, protegendo-as de estresses ambientais, e portando, mantendo a sua viabilidade (DENARDIN e FREIRE, 2000; SANTOS, 2011). Esse efeito protetor se relaciona à sua capacidade de diminuir as transferências de calor, boas propriedades reológicas e alta atividade de água (SCHUH, 2005; FERNANDES JÚNIOR, 2006; SILVA, et al., 2009; SANTOS, 2011).

\section{CONCLUSÕES}

$\mathrm{Na}$ análise da sobrevivência da estirpe UFLA 03-84 (= SEMIA 6461) de Bradyrhizobium sp. em sementes de feijão-caupi cv. BRS Aracê não ocorreu um padrão de crescimento no número de células viáveis do microrganismo em função das concentrações $\left(0.05,0.250,0.500,0.750,1.000,1.250,1.500,1.750\right.$ e $\left.2.000 \mathrm{~g} \mathrm{~L}^{-1}\right)$ do polímero goma xantana e dos períodos de armazenamento $(0,1,2,3,4,12,24,96,192$ e 768 h) das sementes tratadas com as formulações desse biopolímero e com o fungicida carbendazim.

Mesmo sem a observação desse padrão de crescimento, a combinação do inoculante veiculado pela goma xantana com o carbendazim permite a sobrevivência da estirpe avaliada, em muitas das concentrações do polímero e em alguns dos períodos de armazenamento das sementes tratadas com esses produtos.

\section{AGRADECIMENTOS}

Os autores agradecem ao IFMA Campus São Raimundo das Mangabeiras e IFMA Campus Caxias pela obtenção das sementes de caupi, ao IFMA Campus São Luis- Maracanã, pela disponibilidade da infraestrutura (Laboratório de Biotecnologia e Microbiologia do Solo), 


\section{à FAPEMA (FUNDAÇÃO DE AMPARO À PESQUISA DO ESTADO DO MARANHÃO)} pela concessão da bolsa, e aos alunos voluntários do projeto (Luciene Ferreira, Érica França, Narjara Greicy, Ana Michelly e Natália de Jesus).

\section{REFERÊNCIAS}

ARIAS, L.V.A. Inoculação de Azotobacter spp. em sementes de feijão (Phaseolus vulgaris): qualidade fisiológica das sementes e produção de grãos. Dissertação (Mestrado em Engenharia Agrícola) -Universidade Estadual de Campinas, Faculdade de Engenharia Agrícola, Campinas, SP, 2016.

ALMEIDA, L. G. de.; ALCÂNTARA, R. M. C. M. de.; NOBREGA, R. S.; NOBREGA, J. C. A.; LEITE, L. F. C.; SILVA, J. L.da. Produtividade do feijão-caupi cv BR 17 Gurguéia inoculado com bactérias diazotróficas simbióticas no Piauí. Rev.Bras. Ciênc. Agrár. Recife, v. 5, n. 3, p. 364-369, 2010.

BARBOSA, F. R.; GONZAGA, A. C. O. Informações técnicas para o cultivo do feijoeirocomum na Região Central-Brasileira: 2012-2014. Santo Antônio de Goiás: Embrapa Arroz e Feijão, (Documentos, 272), 2012. 247 p.

CAMPO, J. R. et al. Compatibilidade de aplicação de inoculantes com defensivos agrícolas e micronutrientes. In: CAMPO, C. B. H.; SARAIVA, O. F. (Org.). Resultados de pesquisa da Embrapa Soja-2002. Londrina: Embrapa Soja, 2003. p. 20-38. (Documentos, 216).

CARDILLO, B. E. da S. Compatibilidade de fungicida via semente e fixação simbiótica em feijoeiro-comum. 2015. 122 f. Dissertação (Mestrado em Agronomia/Fitotecnia)Universidade Federal de Lavras, Lavras, 2015.

COSTA, I. G. da. Genética de populações segregantes de feijão-caupi quanto a fixação biológica de nitrogênio. 2018. 86 f. Tese (Doutorado em Melhoramento Genético de Plantas) Universidade Federal Rural de Pernambuco, Recife, 2018.

DENADIN, N.D. Avaliação de polímeros para a formulação de inoculantes com Bradyrhizobium japonicum. 1997. 100 f. Tese (Doutorado em Ciência do solo)- Universidade Federal do Rio Grande do Sul, Porto Alegre, 1997.

FARIAS, T. P. Eficiência agronômica de estirpes de rizóbio em Feijão-caupi cultivado em áreas do Maranhão. 2014. 107 p. Dissertação (Mestrado em Ciência do Solo) - Universidade Federal de Lavras, Lavras, 2014.

FERNANDES JÚNIOR, P.I. Composições poliméricas a base de carboximetilcelulose (CMC) e amido como veículos de inoculação de rizóbio em leguminosas. 2006. Dissertação (Mestrado em Ciência do Solo). Universidade Federal Rural do Rio de Janeiro, Seropédica, 2006.

FERNANDES, N. Ferramentas para qualidade de sementes no tratamento de sementes profissional. Avanços no tratamento e recobrimento de sementes. Informativo ABRATES, v. 20, n. 3, p. 56. 2010.

FDA- FOOD \& DRUG ADMINISTRATION. Food additives permitted in food for human consumption: xanthan gum. Federal Register, Washington, v.34, n.53, p.5376, 1969. 
FREIRE FILHO, F. R.; LIMA, J. A. de A.; RIBEIRO, V. Q. Feijão-caupi: Avanços tecnológicos. Ed. Brasília-DF. Embrapa Informática, 2005. 519 p

GARCIA, T. V.; KNAAK, N.; FIUZA, L. M. Bactérias endofíticas como agentes de controle biológico na orizicultura. Arquivos do Instituto Biológico, v.82, p.1-9, 2015.

GUIMARÃES, D. G et al. Desempenho da cultivar de feijão-caupi BRS Nova era sob níveis de irrigação e adubação em ambiente protegido. Cultura Agronômica, Ilha Solteira, v.29, n.1, p. 61-75, 2020.

KINTSCHEV, M. R.; GOULART, A. C. P.; MERCANTE, F.M. Compatibilidade entre a inoculação de rizóbios e fungicidas aplicados em sementes de feijoeiro-comum. Summa Phytopathologica, Botucatu, v. 40, n. 4, p. 338-346, 2014.

KUSDRA, J.F. Influência do Oligochaeta edáfico Amynthas spp. e do Rhizobium tropici no feijoeiro (Phaseolus vulgaris L.). 1998. 116f. Dissertação. (Mestrado em Agronomia). Universidade Federal do Paraná, Curitiba-PR, 1998.

LACERDA, A. M.; MOREIRA, F. M. S.; ANDRADE, M. J. B.; SOARES, A. L. L. Efeito de estirpes de rizóbio sobre a nodulação e produtividade do feijão-caupi. Revista Ceres, v.51, n. 293, p. 67-82, 2004.

LIPS, A.; CAMPBELL,I.J.; PELAN,E.G. Agregation mechanisms in food colloids and the role of biopolymers.Food polymers, gels and colloids. Cambridge,v. 2,p.1 21,1991.

MARTINS, L. M. V.; XAVIER, G. R.; RANGEL, F. W.; RIBEIRO, J. R. A.; NEVES, M. C. P.; MORGADO, L. B.; RUMJANEK, N. G. Contribution of biological nitrogen fixation to cowpea: a strategy for improving grain yield in the semi-arid region of Brazil. Biology and Fertility of Soils, v.38, p.333-339, 2003.

MERCANTE, F.M.; GOI, S.R.; FRANCO, A.A. Importância dos compostos fenólicos nas interações entre especies leguminosas e rizóbio. Revista Universidade Rural, Série Ciências da Vida, v. 22, n.1, p.6-81, 2002.

MONTEIRO, F. P. R.; CHAGAS JUNIOR, A. F.; REIS, M. R.; SANTOS, G. R.; CHAGAS, L. F. B. Efeitos de herbicidas na biomassa e nodulação do feijão-caupi inoculado com rizóbio. Revista Caatinga, Mossoró, v. 25, n. 3, p.44-51, 2012.

MOREIRA, F.M. DE S.; SIQUEIRA, J.O. Microbiologia e Bioquímica do Solo. 2.ed. atual. e ampl. Lavras: UFLA, 2006. 729p.

OLIVEIRA, J. M. B. de. Produtividade de feijão-caupi sob doses e fontes de adubação orgânica no município de Chapadinha-MA. 2019. 28 f. Monografia (Graduação em Agronomia). Universidade Federal do Maranhão, Chapadinha, 2019.

SANTOS, P. C. S.; ALVES, T. R. C.; FREIRES, A. L. A.; NASCIMENTO, L. V.; AMBROSIO, M. M. Q. Efeito da inoculação de rizóbios sobre a germinação e vigor de plântulas de Mimosa tenuiflora Willd. 2017. In: III Simpósio de Ciência e Tecnologia Agroalimentar, 2017. Anais do Simpósio de Ciência e Tecnologia Agroalimentar, 3, 2017. 
SANTOS, A.A. 2011. 58f. Produção de polissacarídeos visando obter insumos biológicos de interesse para agricultura. Dissertação (Mestrado em Ciência do Solo). Universidade Federal Rural de Pernambuco, Recife, 2011.

SANTOS, M. M. S.; ROCHA, W. S.; SILVA JUNIOR, F. R. CHAGAS JUNIOR, A. F; LOPES, R.R. Compatibilidade de tratamentos de sementes e rizóbio in vitro e em casa de vegetação no feijão-caupi. Tecnologia \& Ciência agropecuária, v.12, n.1, p. 15-21, 2018.

SCHLINDWEIN, G. et al. Influência da inoculação de rizóbios sobre a germinação e o vigor de plântulas de alface. Ciência Rural, v.38, n.3, p.658-664, 2008.

SCHUH, C.A. Biopolímeros como suporte para inoculantes. 2005. 81 f. Dissertação (Mestrado em Microbiologia Agrícola e do Ambiente). Universidade Federal do Rio Grande do Sul. Porto Alegre, RS, Brasil. 2005.

SILVA NETO, M.L; SMIDERLE, O. J. S. K.; FERNANDES JÚNIOR, P. I.; XAVIER,G. R.; ZILLI, J. E. Compatibilidade do tratamento de sementes de feijão-caupi com fungicidas e inoculação com estirpes de Bradyrhizobium. Pesquisa Agropecuária Brasileira, 2013. v.48, n.1, p.80-87.

STROSCHEIN, M. R. D.; SÁ, E. L. S.; MACHADO, R. G.; CABRAL, T. L.; BRUXEL, M.; GIONGO, A.; FONTOURA, R. C. Caracterização e influência de rizóbios isolados de alfafa na germinação e desenvolvimento inicial de plântulas de arroz. Ciência Rural, Santa Maria, v.41, n.10, p.1738-1743, 2011.

SILVA, M. F.; OLIVEIRA, P. J.; XAVIER, G. R., RUMJANEK, N. G.; REIS, V. M. Inoculantes formulados com polímeros e bactérias endofíticas para a cultura da cana-de-açúcar. Pesquisa Agropecuária Brasileira, Brasilia, v.44, p.1437- 1443,n.11, 2009.

SOUZA, D.A. Germinação e desenvolvimento inicial de Vigna unguiculata (L.) Walp. inoculada com bactérias diazotróficas. 2017. Monografia (Graduação de Tecnologia em Agroecologia) - Universidade Federal do Recôncavo da Bahia, BA, 2017.

UDVARD, M.K.; DAY,D.A. Metabolite transport across symbiotic membranes of legume nodules. Annu. Rev. Plant Physiol. Plant Mol. Biol., v.48, p.493-523.1997.

VINCENT, J. M. A manual for the practical study of the root-nodule bacteria. London: International Biological Programme, 1970.

VIEIRA, C.L., FREITAS, A.D., SILVA, A.F., SAMPAIO, E.V.; ARAÚJO, M.S. Inoculação de variedades locais de feijão macassar com estirpes selecionadas de rizóbio. Revista Brasileira de Engenharia Agrícola e Ambiental, 2010, v.14, n.11, p. 1170-1175.

ZAHRAN, H.H. Rhizobium-Legumes symbiosis and nitrogen fixation under severe conditions and in na aride climate. Microbiology and Molecular Biology Reviews,v.63, n.4, p.968-989. 1999.

ZAMBOLIM, L. Importância do tratamento de sementes no manejo integrado de doenças. In: SIMPÓSIO BRASILEIRO DE PATOLOGIA DE SEMENTES, 8, 2004, João Pessoa, PB. Palestras e Resumos..., João Pessoa: Tropical Hotel Tambaú, 2004.p.94-94. 
SOBREVIVÊNCIA DE RIZÓBIO EM SEMENTES DE FEIJÃO CAUPI TRATADAS

ZILLI, J. É. et al. Eficiência simbiótica de estirpes de Bradyrhizobium isoladas de solo do Cerrado em caupi. Pesquisa Agropecuária Brasileira, v. 41, n. 5, p. 811-818, 2006. 